\title{
VARIABILIDADE INTERANUAL DA PRECIPITAÇÃO SIMULADA PELO REGCM4: ANÁLISE DE SENSIBILIDADE À VARIAÇÃO DE ESQUEMAS DE SUPERFÍCIE
}

\author{
Marta Llopart ${ }^{1}$, Nathalie Boiaski ${ }^{2}$, Rosmeri P. da Rocha ${ }^{1}$ \\ ${ }^{1}$ Instituto de Astronomia, Geofísica e Ciências Atmosférias (IAG-USP) \\ ${ }^{2}$ Universidade Federal de Santa Maria (UFSM) \\ marta.llopart@iag.uspbr
}

\section{RESUMO}

O objetivo desse trabalho foi analisar a variabilidade interanual da precipitação sobre a AMZ e LPB simulada pelo RegCM4 utilizando duas diferentes parametrizações de superfície.

\begin{abstract}
The goal of this study was analyzed the interannual variability of precipitation over the AMZ and LPB simulated by RegCM4 using two different land surface schemes.
\end{abstract}

\section{INTRODUÇÃO}

O fenômeno El Niño-Oscilação Sul (ENOS) é o principal modo de variabilidade na escala interanual. A sua influência no regime de precipitação na América do Sul é conhecida e bem documentada na literatura (Grimm et al. 1998). No entanto, pouco se sabe do papel da superfície terrestre na variabilidade climática interanual e na ocorrência de eventos extremos hidroclimáticos em regiões com potenciais impactos ambientais (naturais e/ou antropogênicos).

\section{OBJETIVO}

Este trabalho avalia a variabilidade interanual da precipitação simulada pelo modelo climático Regional Climate Model (RegCM4) acoplado a dois diferentes esquemas de superfície para duas diferentes regiões: Amazônia (AMZ) e Bacia do Prata (LPB).

\section{METODOLOGIA}

Foram realizadas duas simulações com o RegCM4 (Giorgi et al. 2012), por um período de 30 anos (1979-2009). As simulações empregaram $50 \mathrm{~km}$ de resolução horizontal, 18 níveis sigma na vertical. As condições iniciais e de fronteira foram obtidas da reanálise EraInterim. $\mathrm{O}$ domínio das simulações realizadas e os sub-domínios utilizados para as análises são mostrados na Figura 1. 


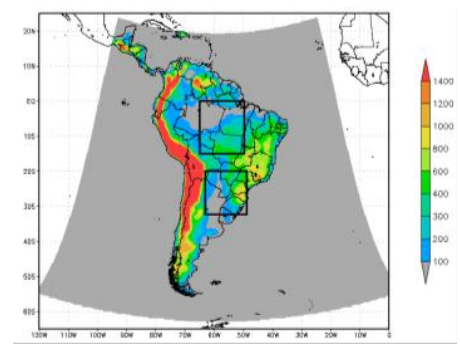

Figura 1.: Domínio utilizado e topografia (m). As caixas identificam as sub-regiões definidas para as análises - AMZ e LPB.

As simulações realizadas diferiram apenas na parametrização de superfície adotada, onde o experimento RegCLM utilizou o modelo de superfície CLM3.5 como condição de fronteira inferior para o RegCM4, já no experimento RegBATS foi prescrito o modelo BATS.

Os dados mensais de precipitação foram filtrados na escala interanual, retendo-se períodos superiores a 12 meses, por meio da Transformada Rápida de Fourier, obtendo-se uma série de anomalias interanuais de precipitação para cada região. Posteriormente, foram calculados os percentis de $25 \%$ e $75 \%$ dessas anomalias para determinar os limiares para eventos extremos secos e úmidos, respectivamente. Deste modo, um evento extremo úmido (seco) ocorre quando o valor da anomalia for acima (abaixo) do percentil de 75\% (25\%). Dados mensais do Climatic Research Unit (CRU) foram utilizados para comparação com os experimentos RegCLM e RegBATS.

\section{RESULTADOS E DISCUSSÃO}

As anomalias interanuais da precipitação para os dados do CRU, RegCLM e RegBATS nas regiões AMZ e LPB, são mostradas na Figura 2. Observa-se que os eventos úmidos na região AMZ (destacados em amarelo) ocorreram em anos de La Niña moderada a forte, exceto no evento em 1981-1982 (linha amarela pontilhada), na qual houve uma La Niña fraca (Figura 2a). Os eventos secos na região AMZ (destacados em cinza), menos frequentes quando comparado aos eventos úmidos, ocorreram em anos de El Niño moderado a forte. $\mathrm{O}$ oposto foi observado na região LPB, no qual os eventos úmidos (em amarelo) ocorreram em anos de El Niño moderado a forte e os eventos secos (em cinza) ocorreram em anos de La Ninã moderada a forte, exceto no evento em 1981-1982 (linha cinza pontilhada), na qual houve uma La Niña fraca (Figura 2b).

Para a região AMZ, o experimento RegCLM apresentou valores dos percentis mais próximos dos valores do CRU, indicando que o RegCM acoplado ao CLM apresenta maior habilidade em simular eventos extremos de baixa frequência para essa região (Figura 3a). Já para a LPB (Figura 3b), a diferença entre os percentis é pequena, mostrando uma similaridade na determinação de eventos extremos de baixa frequência entre as simulações e os dados do CRU. 


\section{CONCLUSÕES}

Para a AMZ, a intensidade de anomalia do RegCLM é mais próxima das observações enquanto o RegBATS amplifica o sinal da anomalia, que pode estar relacionado com os fluxos de superfície. Já para a LPB as duas simulações apresentaram comportamentos muito semelhantes e em alguns eventos ENOS simularam o sinal de forma contrária ao que foi observado.

Para a AMZ, o RegCLM mostra maior habilidade em simular eventos extremos de baixa frequência. Para a LPB, a intensidade dos eventos extremos secos foram melhor simulados pelo RegBATS e os eventos extremos chuvosos pelo RegCLM.

(a) AMZ

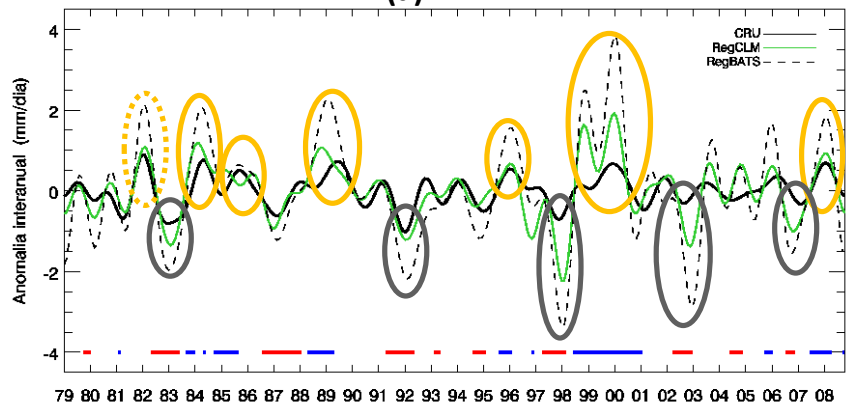

(b) $L$ PB

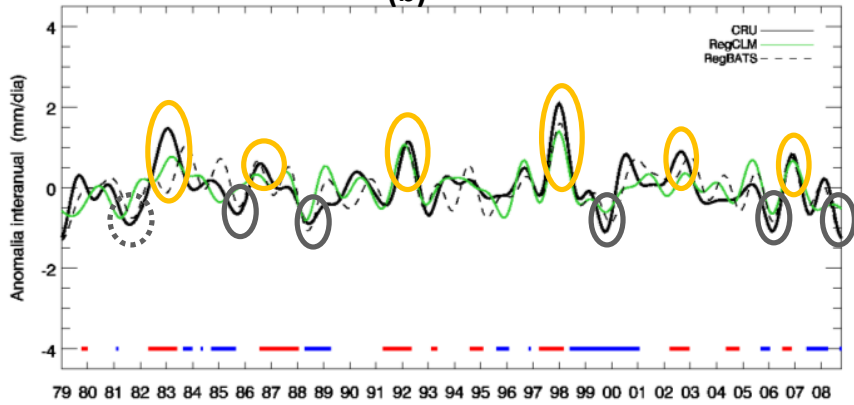

Figura 2.: Anomalias de precipitação na escala interanual: (a) AMZ (b) LPB. A linha vermelha (azul) representa os eventos de El Niño (La Niña) baseado no Oceanic Niño Index (ONI).

(a)

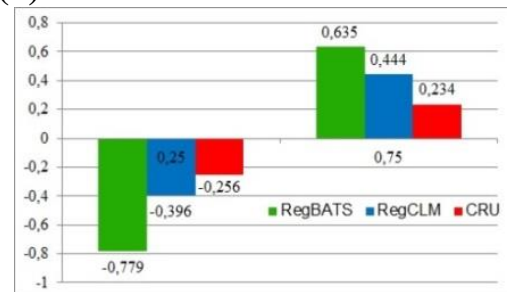

(b)

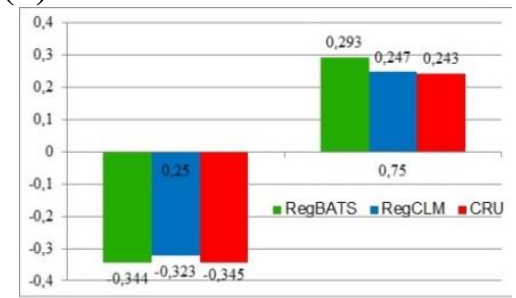

Figura 3.: Percentis de precipitação de $25 \%$ e $75 \%$ para: (a) AMZ (b) LPB

\section{REFERÊNCIAS BIBLIOGRÁFICAS}

Giorgi F, Coppola E, Solmon F et al (2012) RegCM4: Model description and preliminary tests over multiple CORDEX domains, Clim. Res., 52, 7-29, doi:10.3354/cr01018.

Grimm AM, Ferraz SET ,Gomes J (1998) Precipitation anomalies in southern Brazil associated with El Niño and La Niña events. Journal of Climate, 11, 2863-2880. 